\title{
Charging and Discharging Control of Li-Ion Battery Energy Management for Electric Vehicle Application
}

\author{
M. Verasamy ${ }^{1}$, M. Faisal ${ }^{2 *}$, Pin Jern Ker ${ }^{3}$, M A Hannan ${ }^{4}$, \\ ${ }^{1}$ Department of Electrical Power Engineering, College of Engineering, University Tenaga Nasional, 43000, Kajang, Malaysia \\ ${ }^{2}$ International Islamic University Chittagong, Bangladesh \\ *Corresponding author E-mail: M. Faisal (fsl3319@gmail.com)
}

\begin{abstract}
Electric vehicle (EV) is now replacing the conventional fuel driven vehicle as it has strong contribution to face the challenges of global warming issues. This system has the energy storage device which can be introduced by lithium-ion (li-ion) battery banks. Lithium-ion is mostly popular because of its high capacity and efficiency. Nevertheless, li-ion battery needs protective mechanism to control overcharged or undercharged of the cell that can reduce the life expectancy and efficiency. Hence, a control model needs to develop to enhance the protection of battery. Therefore, the key issue of the research is to investigate the performance of Li-ion battery energy management system (BMS) for electrical vehicle applications by monitoring and balancing the cell voltage level of battery banks using Simulink software. A bidirectional flyback $D C-D C$ converter is investigated in the BMS model to control the undercharging or overcharging of cells. An intelligent charge control algorithm is used for this purpose. Backtracking search optimization algorithm (BSA) is implemented to optimize the parameters for generating regulated PWM signal. Obtained results were observed within the safety operating range of Li-ion battery $(3.73 \mathrm{~V}-3.87 \mathrm{~V})$.
\end{abstract}

Keywords: Battery energy management; Charge equalization; Electric Vehicle; Protection; Optimization.

\section{Introduction}

The recent trends of the modern economic development of the automobile and renewable resources are looking forward to solve the global environmental issues. Conventional internal combustion engine (ICE) based vehicles use fossil fuel to drive the vehicle. During combustion, these vehicles dissipate about $85 \%$ of total energy as heat [1] that causes the emission of toxic carbon monoxide, nitrogen oxides, carbon dioxide $\left(\mathrm{CO}_{2}\right)$ and other greenhouse gases (GHGs) [2]. Moreover, human practices and behavior are another significant factor for environmental damages. Different researches on environmental issues are proposing to control public practices and behavior to reduce the negative impact on environment. Besides this, shortage of reserved fuel urges automotive industry to search for ecofriendly energy source.

Malaysian Government has taken the step to lessen $40 \%$ GHG emission by the year 2020 by introducing electric vehicle (EV) and hybrid electric vehicle (HEV). As EV is a clean vehicle with a greater efficiency and pollution free, it can be defined as 'zero emission vehicle'. EV operation depends on the energy storage system from which energy is transferred to the motor to drive the vehicle [3]. EV system comprises of the renewable sources and has remarkable properties to yield the wastage energies from regenerative braking, engine vibration and heat. Moreover, vehicle to grid (V2G) technology facilitates the EV to boost the stability of network by supplying surplus energy to the electricity grid when the power demand reaches the peak.

An electric vehicle is generally comprises of a module charger, electric motor, controller, regenerative braking system, battery pack module and BMS. Storage system requires protective equipment to safe the batteries from damages [4]. Thus, the choice of energy storage, resources and storage management system are vital for modern EV technologies. Although lead-acid is the widely used storage system in the world, lithium-ion battery is gaining more popularity due to its efficient charging and discharging characteristics with improved life cycle.

Previous researches on BMS focused on increasing the life expectancy, safety and efficiency of the battery. As the cell of battery pack undergo multiple times of charge-discharge cycles, they may suffer from overcharge or undercharge problems. The undercharged cell is responsible to reduce the efficiency while overcharged cells can sabotage the storage. Therefore, charge equalization among the cells is vital to increase the battery performance and safety [5].

The proposed algorithm contributes to the equalization technique till all the cells getting equalized accordingly. It allows the undercharged cell to get charged from the battery pack or it supplies surplus energy from the overcharged cell to the battery bank. Hence, the developed mechanism can guard the cell from getting damaged.

This study proposes to develop the BMS with an intelligent charge control technique to investigate the optimum charging and discharging characteristics of storage system. The rest of the paper is organized as follows. In section II, concerning issues of BMS in vehicle application is discussed. Intelligent charge equalization technique is described in section III. Section IV discusses about the simulation model and detailed analysis of charging and discharging characteristics of the proposed model. Finally, conclusions are drawn in section $\mathrm{V}$. 


\section{Concerning Issues of BMS in Vehicle Appli- cation}

Lithium-ion battery has becoming more popular due to its low self-discharge rate, longer life cycle and high energy density. Prime issues of BMS are discussed below.

\subsection{Evaluation of Battery State}

Safety and reliability of battery can be examined by evaluating the battery state of charge (SOC) and state of health $(\mathrm{SOH})$. BMS is unable to reflect the accurate value of $S O C$ due to intermittent nature of environment. Available charge of the battery can be computed by Eq. 1 where $i$ and $C_{n}$ denote the current and maximum charge of battery respectively.

$$
S O C=1-\frac{\int i d t}{C_{n}}
$$

Battery capacity decreases due to the presence of external loads and various chemical reactions in cell. Coulomb counting method is the simplest technique for measuring the battery $S O C$.

$\mathrm{SOH}$ reflects the insight on the current health condition and performance of a battery when compared to a new battery. When battery capacity reduces to $80 \%$ at the beginning of a charging discharging cycle, it may lead to the battery failure. Researchers investigated different techniques to classify $\mathrm{SOH}$ depending on the battery characteristics and testing equipment [6].

\subsection{Battery Modelling}

Developing battery model is challenging due to the complex electrochemical mechanisms in the cell. For instance, characteristics of $\mathrm{LiCO}_{1 / 3} \mathrm{Mn}_{2 / 3} \mathrm{O}_{2}$ and $\mathrm{LiMn}_{2} \mathrm{O}_{4}$ exhibit gradual increase in voltage during charging mode whereas $\mathrm{LiFePO}_{4}$ shows the long straight trend in the similar condition [7]. Internal resistance of the generic model is assumed to be uninterrupted in both charging and discharge mode. Thus, it challenges the accuracy of the model. Moreover, external aspects like discharging current, load and ambient temperature have strong influence on battery model. Therefore, selection of battery model is always the prime concern in BMS.

\subsection{Cell Balancing}

Cells in series connections have different voltage rating. During charging, capacity fade might causes the damage to the cell. While discharging, weakest cells confronted with over-discharging, thus fail prior to the rest. Failure rate is more in series connected cells compare to the individual cell. Therefore, an effective cell balancing technique can be introduced to stable the SOC levels of each cell of battery [8].

Expression of charging-discharging characteristics of li-ion battery can be deduced as equation (2) and (3),

$$
\begin{aligned}
& V_{c h}=E_{0}-K \frac{Q}{Q^{\prime}+0.1 Q} i^{*}-K \frac{Q}{Q^{\prime}-Q} Q^{\prime}+A e^{-B Q^{\prime}}-R i \\
& V_{\text {disch }}=E_{0}-K \frac{Q}{Q-Q^{\prime}} i^{*}-K \frac{Q}{Q-Q^{\prime}} Q^{\prime}+A e^{-B Q^{\prime}}-R i
\end{aligned}
$$

\section{Where}

$V_{c h}=$ battery voltage in charging mode;

$V_{\text {disch }}=$ battery voltage in discharging mode;

$E_{0}=$ constant voltage;

$i=$ current;
$K=$ polarization constant $\left(A h^{-1}\right)$

$R=$ internal resistance $(\Omega)$;

$Q^{\prime}=$ extracted capacity $(A h)$;

$Q=$ maximum capacity $(A h)$;

$A=$ exponential zone voltage $(V)$;

$B=$ exponential zone time constant $(A h)^{-1}$;

$i^{*}=$ low frequency current $(A)$;

Fig. 1 depicts the relationship with cell voltage and SOC by where it shows that cell voltage increases with the charge increases [9].

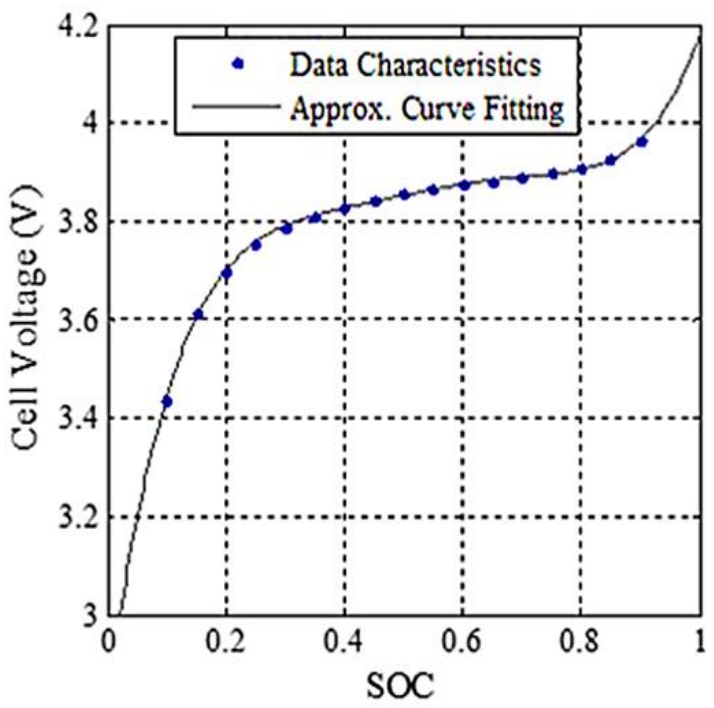

Fig. 1: $S O C-O C V$ characteristics of Lithium-ion battery [9] $S O C$ of the battery can be computed by Eq. 4 [10],

$S O C=S O C_{0}-\frac{\eta}{C} \int_{0}^{T_{e q}} i(t) d t$

Where

$S O C_{0}=$ initial value of SOC;

$C=$ nominal battery capacity;

$T_{e q}=$ equalization time;

$\eta=$ efficiency;

\section{Intelligent Charge Equalization Technique of BMS}

Ideally, common current-common voltage (CC-CV) method is used for charging and discharging of the battery. However, this technique faces the challenge of controlling the charging discharging mechanism. Therefore, intelligent system is required to control the overcharging and under-discharging phenomena of the battery. The error generated in $\mathrm{CC}-\mathrm{CV}$ method can significantly reduce with the proposed BMS mechanism by using BSA optimization technique.

BMS equalizes the series-connected battery pack by using the intel-ligent charge equalization algorithm. Here, cells were monit-ored to record voltage level of individual cell. It is done to determine the cell operating conditions. Standard SOC range for $\mathrm{Li}$ ion battery varies between $3.73 \mathrm{~V}$ to $3.87 \mathrm{~V}$. If there is any mismatch in any cell, equalization algorithm control the bidirectional cell switch to normalize the mismatched cell. Bidirectional DCDC converter composed of forward and reverse converter to charge and discharge the battery accordingly. Controller controlled the current flow from the battery bank to detected undercharged cell [11], [12]. Thus, to fulfil the equalization mechanism, proposed algorithm sensed the individual cell voltage level to find 
the unbalanced cell and thus, permits the converter to exchange energy between target cell and storage system [13]. The algorithm is shown in Fig. 2. In this paper the observation of $\mathrm{CC}$ and $\mathrm{CV}$ method with optimization has clearly investigated.

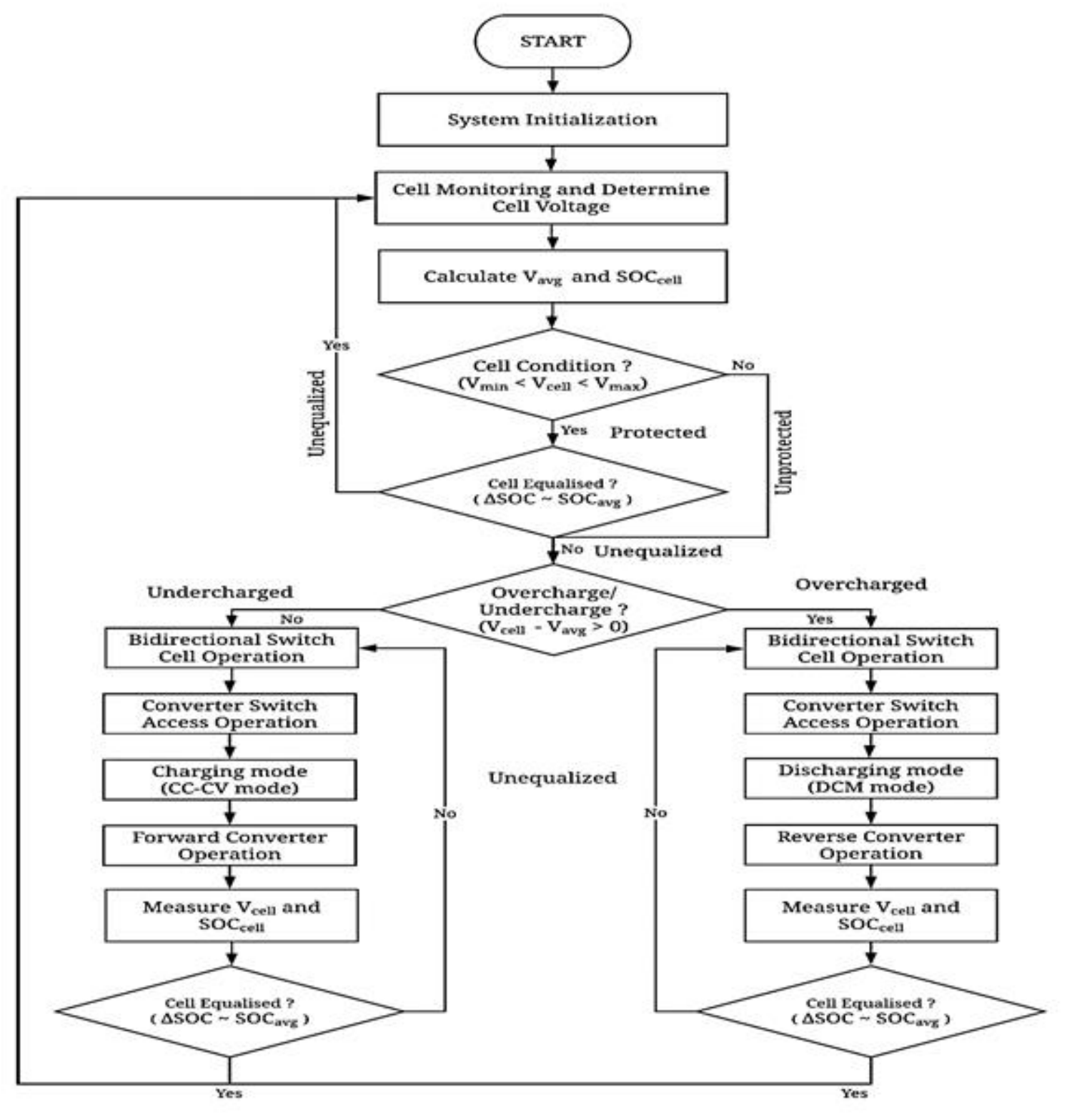

Fig. 2: Flowchart of intelligent charge equalization algorithm

\section{Simulation Model and Result Analysis}

BMS model is designed for testing and analysing the charge equalization performance of li-ion battery pack. The circuit is performed in MATLAB software. Block diagram of proposed model is shown in following figure.

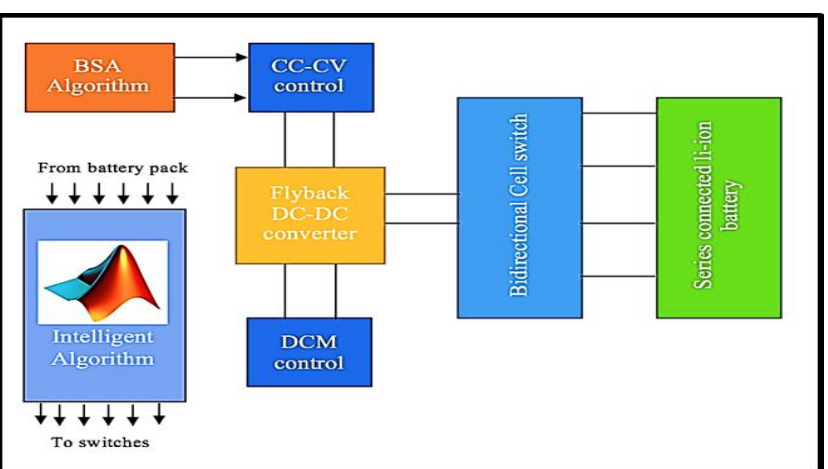

Fig. 3: Proposed BMS model
Fig. 4 shows the schematic diagram of proposed BMS model. Here, the converter, access switch, cell switch and storage systems are connected in such a way that proposed algorithm can control both the switches depending on the cell condition whether they are required to be charged or discharged. Data table of Li-ion battery is presented in Table 1 below.

Table 1: Data Table

\begin{tabular}{|l|l|}
\hline Particulars & Data \\
\hline Nominal voltage & 3.7 Volts \\
\hline Rated capacity & $15.5 \mathrm{Ampere}$-hour \\
\hline SOC & 20 to $80 \%$ \\
\hline Maximum capacity & $16.75 \mathrm{Ampere}$-hour \\
\hline Fully charge current & $4.2 \mathrm{Amp}$ \\
\hline Nominal value discharge current & $2 \mathrm{Amp}$ \\
\hline Internal resistance & $0.0018 \Omega$ \\
\hline
\end{tabular}

Charging-discharging characteristics of li-ion battery are shown in Fig. 5 and Fig. 6 respectively. From these Figs, it can be inferred that cell voltage increases if the charge increases at high rate while cell voltage decreases with the charge decreases at high rate. 


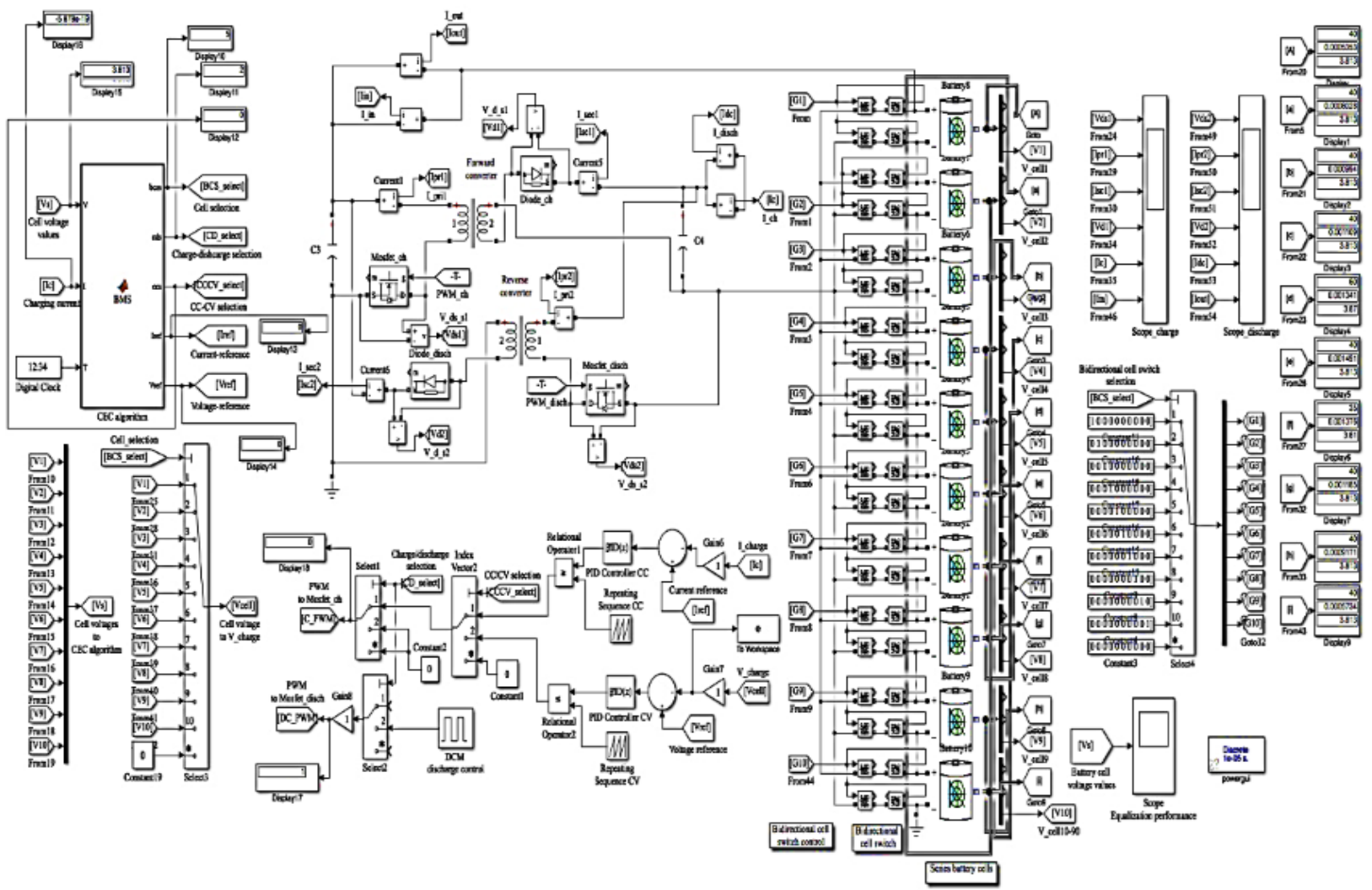

Fig. 4: Schematic diagram of proposed BMS model in MATLAB simulink

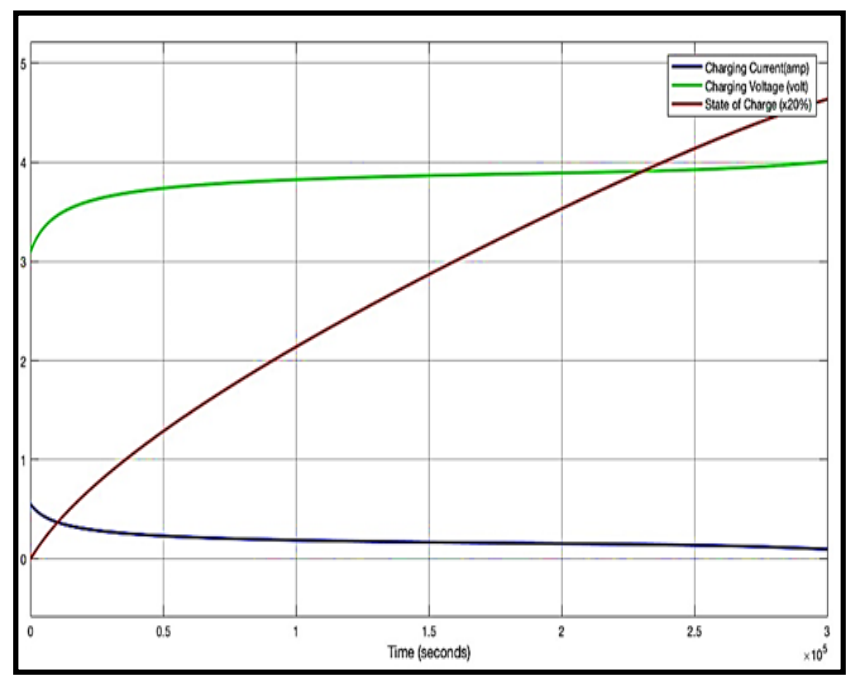

Fig. 5: Charging characteristics of lithium-ion battery

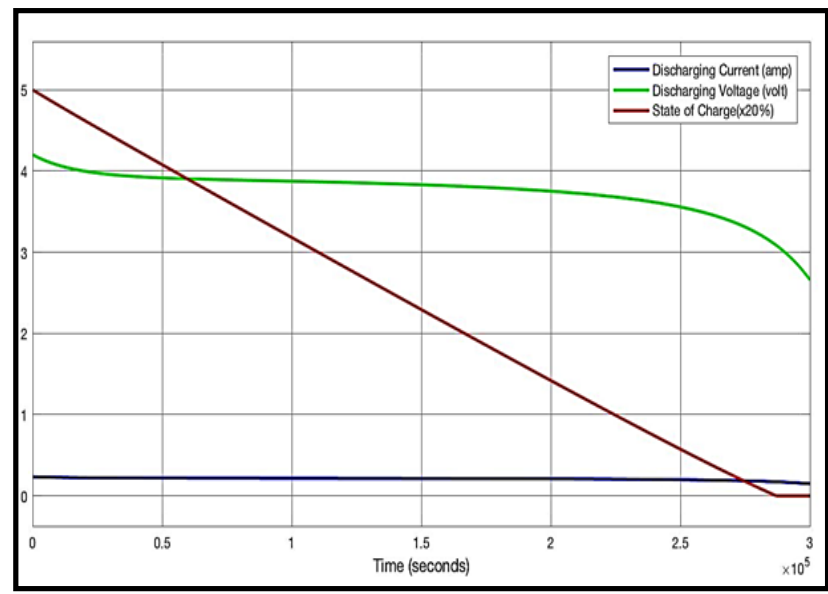

Fig. 6: Discharging waveform of lithium-ion battery
Here, flyback converter operated as forward converter to perform the equalization process by charging the undercharged cell. The characteristic curves of the forward converter is shown in Fig. 7. Here, the waveforms are for the voltage stresses of the MOSFET and forward diode, primary and secondary current of transformer respectively. Value of voltage stresses of MOSFET and diode were obtained as $55 \mathrm{~V}$ and $18 \mathrm{~V}$.

Moreover, performance of the Proposed controller was observed with 100 iterations in BSA algorithm. Obtained result showed the best result with the desired minimum value for the objective function illustrated for the proposed mechanism. Fig. 8 and Fig. 9 depicts the output response curve of the objective function with better accuracy and minimum error in $\mathrm{CC}$ and $\mathrm{CV}$ mode.

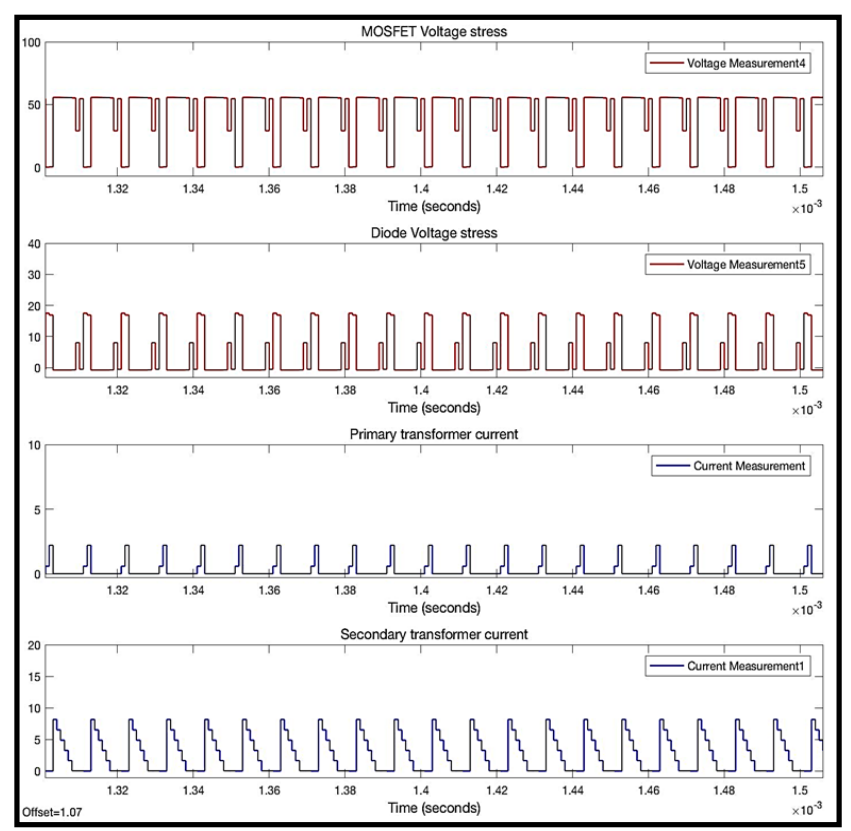

Fig. 7: Forward flyback converter characteristic curves 


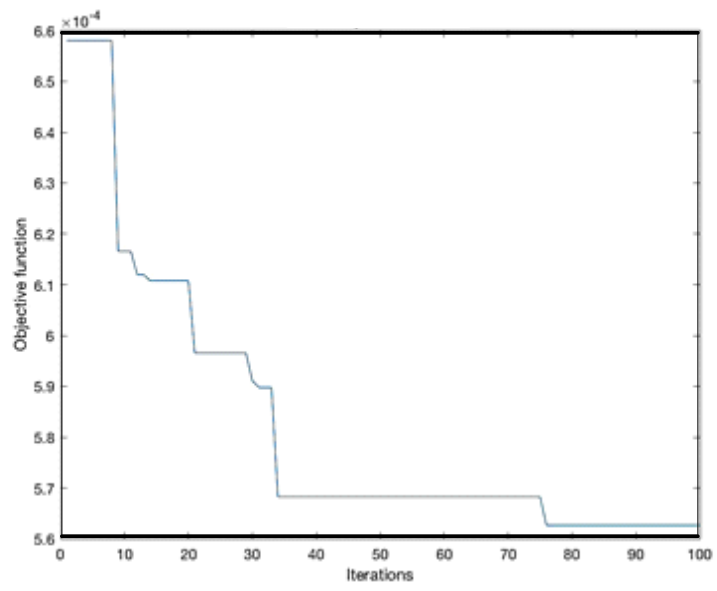

Fig. 8: Objective function optimization curve with CC technique

\section{Conclusion}

The research proposes an optimal BMS mechanism to protect the Lithium-ion storage devices from overcharging and undercharging which will enhance the battery performance and lifecycle in EV applications. The main goal was identified and achieved for the proposed BMS model. Therefore, a BMS model is developed for obtaining the efficient charging and discharging of the storage.

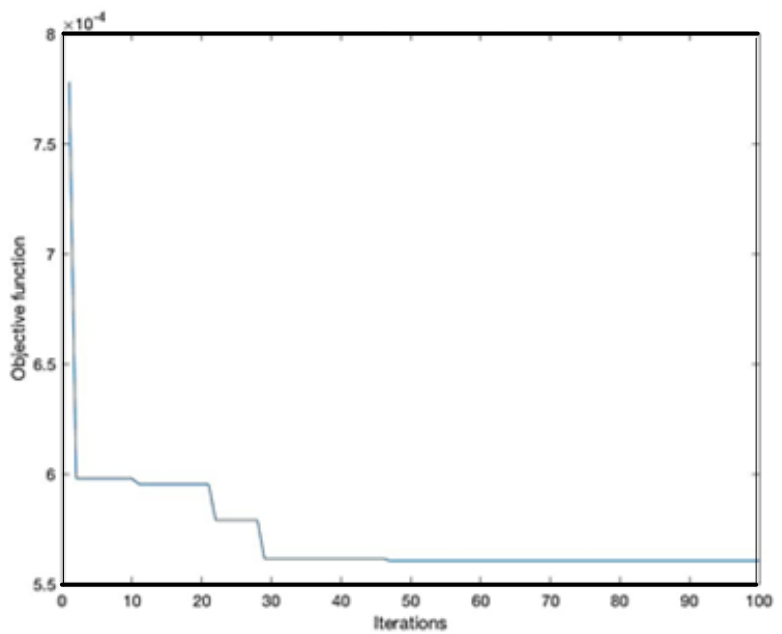

Fig. 9: Objective function optimization curve with CV technique

The objective function was verified with the BSA optimization technique. Obtained result reveals that, proposed control strategy can significantly control the charging-discharging of battery storage system and thus save the energy and prolonged the battery life. So, the outcomes can be treated as the excellent performance for the proposed BMS model for the application in modern EV systems.

\section{Acknowledgement}

The authors acknowledge the financial support provided by Universiti Tenaga Nasional under the grant code RJ010289176/ D/ 2018/J48.

\section{References}

[1] H. D. Yoo, E. Markevich, G. Salitra, D. Sharon, and D. Aurbach, "On the challenge of developing advanced technologies for electrochemical energy storage and conversion," Mater. Today, vol. 17, no 3,pp. 110-121, 2014.
[2] G. Huff et al., "DOE/EPRI 2013 electricity storage handbook in collaboration with NRECA,” Rep. SAND2013, July, p. 340, 2013.

[3] Hussain A, Hannan MA, Mohamed A, Sanusi H, Ariffin AK. Vehicle crash analysis for airbag deployment decision. Int J Automot Technol 2006;7:179-85.

[4] Y. Jingyu, "Intelligent battery management system for electric vehicles," 2016.

[5] V. Madanipour, M. Montazeri-Gh, and M. Mahmoodi-k, "Multiobjective component sizing of plug-in hybrid electric vehicle for optimal energy management," Clean Technol. Environ. Policy, vol. 18 , no. 4, pp. 1189-1202, 2016

[6] H. Rahimi-Eichi, U. Ojha, F. Baronti, and M. Chow, "Battery Management System: An Overview of Its Application in the Smart Grid and Electric Vehicles,” Ind. Electron. Mag. IEEE, vol. 7, no. June, pp. 4-16, 2013

[7] E. C. Evarts, "Lithium batteries: To the limits of lithium," Nature, vol. 526, no. 7575, pp. 93-95, 2015.

[8] Z. C. Gao, C. S. Chin, W. D. Toh, J. Chiew, and J. Jia, "State-ofCharge Estimation and Active Cell Pack Balancing Design of Lithium Battery Power System for Smart Electric Vehicle," J. Adv. Transp., vol. 2017, 2017.

[9] M. A. Hannan, M. M. Hoque, P. J. Ker, R. A. Begum, and A. Mohamed, "Charge equalization controller algorithm for seriesconnected lithium-ion battery storage systems: Modeling and applications," Energies, vol. 10, no. 9, pp. 1-20, 2017.

[10] X. Hu, N. Murgovski, L. M. Johannesson, and B. Egardt, "Optimal dimensioning and power management of a fuel cell/battery hybrid bus via convex programming," IEEE/ASME Trans. Mechatronics, vol. 20, no. 1, pp. 457-468, 2015.

[11] Subiyanto, A. Mohamed, and M. A. Hannan, "Maximum power point tracking in grid connected PV system using a novel fuzzy logic controller," 2009 IEEE Student Conf. Res. Dev., no. SCOReD, pp. 349-352, 2009.

[12] B. Sakhdari and N. L. Azad, "An optimal energy management system for Battery Electric Vehicles," IFAC-PapersOnLine, vol. 28, no. 15, pp. 86-92, 2015.

[13] Q. Zhang and W. Deng, “An adaptive energy management system for electric vehicles based on driving cycle identification and wavelet transform," Energies, vol. 9, no. 5, 2016. 